framum

Sociológico

\section{Forum Sociológico}

Série II

$36 \mid 2020$

Viver a mobilidade: Percursos, permanências e registos

\title{
Contributos para a compreensão da mobilidade : Uma análise às travessias pedonais
}

Contributions for understanding mobility: An analysis of pedestrian crossings

Márcia Silva, Emília Araújo e Rita Ribeiro

\section{(2) OpenEdition \\ Journals}

Edição electrónica

URL: https://journals.openedition.org/sociologico/9111

DOI: $10.4000 /$ sociologico. 9111

ISSN: $2182-7427$

Editora

CICS.NOVA - Centro Interdisciplinar de Ciências Sociais da Universidade Nova de Lisboa

Edição impressa

Paginação: $37-45$

ISSN: 0872-8380

Refêrencia eletrónica

Márcia Silva, Emília Araújo e Rita Ribeiro, «Contributos para a compreensão da mobilidade : Uma análise às travessias pedonais», Forum Sociológico [Online], 36 | 2020, posto online no dia 09 outubro 2020, consultado o 31 março 2022. URL: http://journals.openedition.org/sociologico/9111 ; DOI: https://doi.org/10.4000/sociologico.9111 


\title{
CONTRIBUTOS PARA A COMPREENSÃO DA MOBILIDADE: UMA ANÁLISE ÀS TRAVESSIAS PEDONAIS \\ CONTRIBUTIONS FOR UNDERSTANDING MOBILITY: AN ANALYSIS OF PEDESTRIAN CROSSINGS
}

\author{
Márcia Silva \\ Centro de Estudos de Comunicação e Sociedade, Instituto de Ciências Sociais, Universidade do Minho, Portugal \\ Emília Araújo \\ Centro de Estudos de Comunicação e Sociedade, Instituto de Ciências Sociais, Universidade do Minho, Portugal \\ Rita Ribeiro \\ Centro de Estudos de Comunicação e Sociedade, Instituto de Ciências Sociais, Universidade do Minho, Portugal
}

\begin{abstract}
Resumo
Existem vários modelos de travessias pedonais que são acompanhados de pressupostos diversos sobre o comportamento dos peões durante o atravessamento. Neste artigo cruzam-se contributos de várias áreas científicas acerca dos tipos e usos das travessias pedonais e analisam-se os resultados de um estudo realizado sobre uma travessia pedonal sem sinais luminosos localizada na cidade de Braga. O estudo, que pretendeu caracterizar como os peões e automobilistas usam uma travessia, serve de fundamento empírico para a construção de um esboço de uma problemática acerca das travessias pedonais. Foi realizado durante o ano de 2019, com recurso a inquérito por questionário e observação directa. Assim, e de forma exploratória, o artigo permite identificar algumas das principais interrogações de ordem sociológica relevantes para o entendimento e a intervenção nas esferas da segurança rodoviária nas cidades e que implicam o planeamento e a tipologia de travessias pedonais, assim como o reforço do trabalho interdisciplinar sobre o tema.
\end{abstract}

Palavras-chave: travessia pedonal, mobilidade, segurança, automóvel

\begin{abstract}
There are several types of pedestrian crossings that are accompanied by different assumptions about the behaviour of pedestrians. This article considers contributions from various scientific areas about the types and uses of pedestrian crossings. It also considers the results of a study carried out on a pedestrian crossing without light signals located in the city of Braga. The study, which aimed to characterize how pedestrians and car drivers use the crossing, serves as empirical support for the theoretical construction of a problematic on the subject. It was carried out during 2019, using a questionnaire survey and direct observation. In an exploratory way, the article allows to identify some of the main sociological questions for the understanding and intervention in the spheres of road safety in cities and which imply the planning and the typology of pedestrian crossings, as well as the reinforcement the interdisciplinary work on the topic.
\end{abstract}

Keywords: pedestrian crossings, mobility, safety, automobile

\section{Introdução}

A experiência de vida nas cidades está bastante dependente da forma como o espaço físico se organiza e se dispõe a ser apropriado e vivido.
O aproveitamento intensivo e comercial dos territórios tem contribuído para a redução dos espaços públicos nas cidades (Harvey, 2012). No caso de Portugal, o grau elevado de automobilização oferece a multiplicação de espaços convidativos ao uso 
do automóvel, o que contribui ainda mais para o declínio da convivialidade nas cidades (Silva, Araújo \& Ribeiro, 2019).

As travessias pedonais cumprem principalmente a função manifesta de permitir a passagem em segurança de pessoas em territórios que foram atribuídos aos veículos automobilizados. A origem e a proliferação das travessias decorrem das mudanças que atingiram e transformaram a paisagem urbana ao longo das últimas décadas. Os contributos teóricos de Edward Soja (1989), David Harvey (1989, 2012), John Urry $(2004,2005)$ ou Mimi Sheller $(2004,2011)$ são significativos para esta problemática. Permitem afirmar que o automóvel reconfigurou profundamente as identidades, por se constituírem como um elemento integrante dos lugares (Sales, 2018).

Não existe literatura sociológica sobre as travessias pedonais e, em grande parte, tal explica-se pelo facto de serem concebidas como obras de engenharia, por um lado, e como elementos naturais do planeamento urbano, por outro. Acrescente-se, aliás, que o próprio planeamento urbano privilegia as vertentes técnico-financeiras, em detrimento das vertentes participativas e experienciais ou fenomenológicas.

Não obstante a ausência de debate teórico específico sobre as travessias pedonais, existem diversos estudos sobre segurança rodoviária, mobilidade e transporte, modos de apropriação do espaço urbano, entre outros que, de forma cruzada, contribuem para suportar dois objectivos: i) conceber a travessia pedonal como um elemento estruturante do dia-a-dia dos actores sociais e ii) explicitar os elementos de ordem sociológica fundamentais para a tomada de decisão acerca destes territórios de sentido e experiência. Com efeito, a questão mais premente que se impõe em relação à dimensão sociológica das travessias pedonais prende-se com a segurança.

Neste texto elencaremos algumas questões fundamentais na problematização das travessias pedonais, principalmente a dois níveis: como espaço-tempo de limbo e de transição que oferece diversas perspectivas de interpretação por parte, nomeadamente, dos peões e dos condutores, e como elementos fundamentais de política pública para a qualidade de vida e a sustentabilidade.

O texto decorre de uma reflexão a propósito do estudo promovido no âmbito do projeto BUILD (Braga Urban Innovation Laboratory Demonstrator) (Silva et al., 2019), coordenado pela Câmara Municipal de Braga, com a participação da Universidade do Minho e financiado pelo Fundo Ambiental. Trata-se de um projecto orientado para a promoção de intervenções no espaço e nos modos de vida, no sentido da adopção de políticas e de comportamentos sustentáveis e promotores de descarbonização na cidade. A travessia em estudo situa-se em São
Vicente, na cidade de Braga, na Rua Conselheiro Bento Miguel, em frente a uma escola.

Numa perspectiva exploratória e heurística, intenta apresentar um esboço de uma problematização sociológica das travessias pedonais, minimamente instrutiva da relevância da Sociologia na política pública para o espaço e o território, consolidando algumas ideias acerca das complexidades sociais e psicológicas de alguns objectos vulgarmente tidos por adquiridos.

Assim, e seguindo esta orientação exploratória, o texto divide-se em três partes principais: primeiro, é introduzido um esboço do problema, propondo as principais assunções acerca da função das travessias, tipologias e modos de articulação com a "sociedade automobilizada". Num segundo momento, esclarecemos alguns detalhes metodológicos sobre a recolha e análise dos dados usados ao longo do texto. No terceiro ponto descrevemos quais os principais contributos que o estudo daquela travessia providenciou, no sentido do reforço dos argumentos apresentados. Finalmente, apresentam-se algumas considerações finais que seguem, igualmente, um registo exploratório.

\section{O problema}

O interesse mais imediato em problematizar as travessias pedonais decorre do facto de serem imediatamente reconhecíveis como lugares com elevado potencial de sinistralidade. Segundo dados da Autoridade Nacional de Segurança Rodoviária (ANSR, 2018), o número de atropelamentos mais significativo observa-se no atravessamento em travessias pedonais sinalizadas. Em 2018, registaram-se 2351 atropelamentos em travessias sinalizadas, seguindo-se o atropelamento em plena faixa de rodagem (628 atropelamentos).

Por exemplo, as travessias em áreas de maior circulação de crianças, junto das escolas, são objecto de sinalização especial. Todavia, e ainda sem dados estatísticos específicos sobre o fenómeno, as crianças continuam a ser vítimas de atropelamento em travessias pedonais, especialmente quando estas não têm semáforos. De facto, o debate é conduzido no sentido da discussão das implicações da sociedade automobilizada e das tentativas actuais de retracção do tráfego automóvel nas cidades (Cresswell, 2010).

A sociedade automobilizada expandiu-se histórica e socialmente, a par da sofisticação de meios de redução do tempo-distância (Harvey, 1989, 2012; Massey, 1994; Sales, 2018). Ela é promotora da velocidade, tendo ancorada a categorização distintiva entre dois actores: de um lado, o que circula a pé - o peão - e, de outro, o que circula de carro - o condutor. A ambos é atribuído um estatuto (constituído de papéis e expectativas) que conforma e, de algum modo, acautela possíveis 
responsabilidades e/ou sanções. A instituição destes estatutos acompanha-se de um dispositivo legal relativamente detalhado que, teoricamente, assegura as margens de liberdade e de autonomia de cada actor no decurso das acções que desenvolvem dentro das delimitações territoriais conferidas nos artigos $103 .^{\circ}$ e $104 .^{\circ}$ do Código da Estrada. Trata-se de um quadro legal que, não obstante estar desenvolvido e ser objecto de acções de informação e de formação, é relativamente desconhecido de tais actores no espaço físico em concreto, principalmente por parte de quem circula a pé.

Ademais, na prática quotidiana, tanto peões como condutores experienciam e protagonizam diversas lutas que visam manter as suas identidades "separadas", uns enquanto peões e outros enquanto condutores. Os quadros regulatórios evidenciam o interesse no estabelecimento de modos de convivência e de comunicação entre peões e condutores.

A problematização sociológica das travessias pedonais é ainda escassa e exige contributos de áreas e de autores que, em circunstâncias diversas, analisam as políticas de segurança rodoviária, a administração do território e modos de vida, a dinâmica dos grupos e os modos de vida nas cidades e, fundamentalmente, os efeitos da automobilização dos centros das cidades.

Mesmo do ponto de vista das políticas no âmbito da segurança rodoviária, escasseiam estudos sociológicos que relacionem os eixos legais e de controlo policial com os eixos de promoção de política pública integrada para o espaço e o território. Isto é, que incluam a análise de dimensões pouco ou nada consideradas, em termos da edificação dos empreendimentos infra-estruturais (localização, qualidade dos materiais, tipologias e níveis de segurança associados) e dos tecidos sociais envolventes, incluindo características sociodemográficas e socioeducacionais, dos modos de vida das populações, organização das actividades e aspirações. Isso implica a análise do grau de participação pública na política para o espaço e o território. As travessias pedonais são, a este respeito, um dos elementos que compõem um campo de reflexão e de intervenção muito mais vasto, que interpela directamente o modo como a política central e local entende a segurança rodoviária e o quanto a disposição física dos territórios afecta a qualidade de vida e os estados psicológicos dos cidadãos.

Dada a complexidade e a escassez de estudos no âmbito das travessias, o intento é esclarecer, ainda de forma preliminar, de que modo estes elos podem ser estabelecidos, partindo da reunião de contributos teóricos de algumas dessas áreas e autores e da discussão do processo e dos resultados objectivos no diagnóstico ao uso da travessia pedonal. Para tal, destacamos três temas principais na problematização das travessias: i) as questões relativas ao atravessamento propriamente dito e aos comportamentos dos peões e condutores; ii) os contributos mais relacionados com o entendimento das travessias como uma extensão da persistência e enraizamento da sociedade automobilizada, nos termos descritos acima; e iii) as conclusões relativas ao modo como as tipologias das travessias potenciam subjectividades e acções específicas.

\section{$\mathrm{O}$ atravessamento das travessias pedonais}

Atendendo a esta conotação imediata entre travessia pedonal e acidente, um dos principais focos dos estudos existentes acerca das travessias pedonais incide sobre o comportamento dos peões. Estas pesquisas debruçam-se sobre as experiências e as percepções dos sujeitos no momento do atravessamento (Ariotti, Cybis \& Ribeiro, 2006; Goh, Subramaniam, Wai \& Mohamed, 2012; Gualberto \& Barbosa, 2016; Ibrahim, Kidwai \& Karim, 2005; Sisiopiku \& Akin, 2003). As suas contribuições são importantes para a pesquisa que se realizou em Braga, pois elas estabelecem algumas conclusões no que respeita a dois tópicos fundamentais: i) o comportamento dos peões e dos condutores antes e durante a travessia e a relação destes com o tipo de travessia, nomeadamente em termos de segurança; e ii) a relevância de variáveis, como o género ou a idade, na configuração dos modos de atravessamento e uso da travessia.

Neste alinhamento, destacam-se as pesquisas de Sisiopiku e Akin (2003) e Liu, Silva e Seco (2000), que classificam dois tipos de peões: i) segundo o modo de atravessamento (os "prudentes", que atravessam nos locais apropriados e os "imprudentes", os que atravessam fora das travessias pedonais), e ii) segundo o grau de obediência em relação ao sinal luminoso. Adianta-se que, no grupo dos "prudentes", estão os "obedientes" que aguardam o sinal luminoso para o atravessamento e os "oportunistas" que atravessam enquanto o sinal está vermelho para os peões.

Outros estudos apresentam conclusões acerca da relação entre as travessias pedonais e a qualidade do planeamento urbano, em termos de concepção e implementação das travessias, bem como de análise dos efeitos destes empreendimentos na organização do espaço físico. Além disso, trabalhando com diversas variáveis sociológicas e buscando problematizar dimensões sociais, permitem-nos demonstrar o interesse e a pertinência de entender as travessias pedonais como elementos sociotécnicos e políticos que requerem a análise integrada das vivências e intervenções no espaço. Isto na medida em que as travessias pedonais resultam historicamente de um tipo de política de apropriação e organização do espaço que privilegia a circulação automóvel e que desencadeou a planificação da "cidade dos carros". 
As travessias pedonais e a "cidade dos carros"

A literatura do âmbito dos estudos sociais da ciência (Premebida, Neves \& Darte, 2015) permite perspectivar esta tendência, sob o ângulo da importância que a tecnologia e os objectos tecnocientíficos (como são os automóveis) adquiriram na sociedade portuguesa, principalmente a partir dos anos 90 do século XX. A este respeito, há duas realidades que são muito características da cidade de Braga: i) do ponto de vista político, a adaptação da cidade ao automóvel (em termos de construção e alargamento de vias e construção de grandes parques de estacionamento), e ii) do ponto de vista da experiência da cidade, o declínio da dimensão sensorial, subjectiva e experiencial da cidade, em face da influência constante do automóvel, que se tornou dominante nas relações de apropriação do espaço. Esta realidade é observável no controverso aproveitamento de espaços para parqueamento de carros nas partes mais antigas das cidades, tal como também se verifica em Braga.

Ainda sob a orientação dos estudos sociais da ciência, que preconizam a leitura e a conceptualização do social a partir da co-presença dos objectos tecnocientíficos (Latour, 2005; Webster, 1991), as travessias pedonais podem ser apresentadas num duplo sentido. Por um lado, formas de promoção da circulação a pé e meios de "devolução" do espaço da cidade aos seus habitantes e aos cidadãos, facilitando consumos mais intensivos dos "lugares". Por outro, como veículos de "facilitação" da circulação e da acomodação dos meios automobilizados e regulação dos fluxos de tráfego, o que está em linha com a assunção apresentada acima sobre o ainda dominante paradigma da "cidade dos carros".

As cidades propõem-se hoje a planear a "devolução" de espaços ao caminhar e, tal como é desígnio do projecto que mencionámos neste texto - o projeto BUILD -, a desencadear "medidas" de controlo ambiental e descarbonização. O diagnóstico sobre a localização, tipo e modos de uso das travessias pedonais insere-se nesse desígnio, uma vez que permite estabelecer conclusões sobre a necessidade das mesmas, a intensidade de tráfego e o tipo de fluxo e a adequação da travessia ao tipo de população usuária.

Todavia, é esperado que estas medidas de análise e de diagnóstico, que incluem o estudo da segurança percebida das mesmas, não seja subordinado nem à naturalização do poder determinativo do automóvel (da circulação e acondicionamento do automóvel), nem ao cálculo de indicadores de medida que entram em contradição com os próprios desígnios das "medidas" para a sustentabilidade ambiental. Referem-se, a este respeito, os indicadores "tempo-distância" e "custos de investimento" nas travessias e correlacionados com a segurança das mesmas, em face da circulação de peões.
Nota-se, assim, que as travessias pedonais merecem não só o cruzamento dos diversos contributos de diferentes áreas científicas, mas também o desenvolvimento de uma análise que interroga persistentemente as políticas públicas (centrais e locais) para o território, sob o prisma da importância dada à auscultação e à participação dos cidadãos. Frise-se, a este respeito, o facto de o desenho e a decisão sobre a implementação das passadeiras estarem ancoradas cada vez mais em perspectivas que apresentam três características principais.

Primeiro, tendem a manter a superioridade dos objectos técnicos no espaço, maioritariamente devido ao contributo que evidenciam em termos de poupança de tempo - note-se o investimento em veículos "sustentáveis" motorizados. Tal como Machado Pais explicita (2010), a dinâmica da vida quotidiana actual que se alimenta da "lufa-lufa diária", marcada pela compressão do tempo. Isto é, a necessidade de chegar rapidamente a vários "locais" onde se permanece o mínimo tempo possível (justamente, para cumprir a variedade de realizações). Geetam Tiwari e outros (2007) defendem, aliás, que reduzir o tempo de espera pode diminuir a probabilidade de os peões serem atropelados por um veículo motorizado.

Segundo, assumem e naturalizam os pressupostos da "sociedade de risco" (Beck, 2011), isto é, antecipam a necessidade de os peões e condutores serem "responsáveis" e "autónomos" na tomada de decisões, particularmente no que se refere a zelar pela sua segurança e a dos outros.

Terceiro, presume-se que as travessias são pontes facilitadoras da socialização e de comunicação no espaço que normalmente fica limitado pela circulação automóvel ou outro tipo de empreendimento.

No estudo de que se dá conta neste texto, cruzaram-se estas diversas assunções e, ainda que ela seja assumidamente condicionada e limitada, considerou-se a capacidade de agenciamento por parte dos sujeitos a dois níveis: i) na definição dos seus próprios modos de uso e apropriação da passadeira, que podem ser entendidos como "infractores"; e ii) na problematização da travessia pedonal como objecto sociotécnico, capaz de revelar relações dos sujeitos entre si (enquanto peões, condutores, especialistas e/ou tomadores de decisão) e com outros elementos e processos não humanos.

\section{A tipologia das travessias pedonais}

Com efeito, a engenharia analisa várias dimensões das travessias pedonais e tem sistematizadas as suas principais vantagens e desvantagens (Seco, Macedo \& Costa, 2008). Existem diversas motivações para o desenvolvimento, escolha e implementação de travessias pedonais. Uma das mais importantes tem sido o investimento financeiro que implicam. 
Uma travessia sem regulação por sinais luminosos implica custos consideravelmente mais baixos comparativamente a uma travessia com sinais luminosos. Todavia, é muito mais susceptível de acidente e infracção (Cambon de Lavalettet al., 2009).

$\mathrm{Na}$ perspectiva dos autores, as travessias, mesmo as que incorporam sinais luminosos tipo semáforos, também são susceptíveis de desencadearem comportamentos de risco, particularmente por parte dos peões que, amiúde, atravessam sem respeitarem os sinais luminosos (Goh et al., 2012). Da literatura produzida decorre a ideia de que as travessias pedonais, atendendo ao modo como se apresentam assinaladas no espaço da cidade, desencadeiam comportamentos diversos (Goh et al., 2012). Parte destes comportamentos é esperada, outra parte é de tipo espontâneo, e pode fazer perigar a segurança (como criar caminhos paralelos às travessias, atravessar de forma oblíqua ou contornar os peões).

\section{Metodologia}

O texto, tal como proposto, segue uma orientação exploratória, por dois motivos: i) não se dispõe de literatura sociológica específica sobre travessias pedonais, e ii) o estudo empírico mobilizado providencia dados que, embora sejam consistentes com estudos realizados noutras áreas e sobre temáticas afins, são circunscritos a um único caso analisado, no decurso de um projecto de investigação e intervenção mais vasto (o projecto BUILD, apresentado acima).

Ainda que os resultados do diagnóstico efectuado acerca da travessia situada em São Vicente, em Braga, tenham sido fundamentais para a progressão e avaliação do projecto citado, o presente texto mobiliza-os, na tentativa de esboçar uma construção do objecto de estudo (as travessias), almejando potenciar o interesse em ampliar o estudo crítico sobre o tema. É neste sentido que os resultados surgem documentados no texto como contributos que decorrem da recolha de informação de carácter quantitativo e qualitativo através de três técnicas de investigação: a observação directa e sistemática no local da travessia; o inquérito por questionário aos encarregados de educação dos estudantes do colégio servido pela travessia e a análise de fotografias realizadas no local, ao longo do tempo em que decorreu a observação.

No uso de todas estas técnicas foram seguidos os procedimentos éticos e deontológicos condizentes com a protecção de dados. A observação directa, realizada no local, incluiu o registo escrito de informações (em formato diário), a recolha de fotografia nos momentos de atravessamento e o registo em vídeo dos fluxos na travessia. Optou-se pelo registo vídeo, atendendo a que se trata de um assunto muito susceptível de respostas de fachada.
O registo em vídeo e fotografia assentou numa óptica de complementaridade e enriquecimento (Campos, 2011).

Deste modo, o registo em vídeo, realizado pelas autoras, decorreu entre Novembro de 2018 e Março de 2019. Para reduzir o viés expectável, o registo foi realizado em diversos dias e em diferentes períodos do dia, num total de 82 dias. No total, obtiveram-se 9 horas de gravação, na base da qual foram delimitadas categorias que conduziram à construção de uma base de dados posteriormente sujeita a análise em SPSS.

Por se tratar de um estudo na altura circunscrito a uma travessia específica e considerando que a análise do registo vídeo providenciara informação consistente sobre o fluxo de passantes, características sociográficas e comportamentos mais frequentes na travessia, foi elaborado e administrado um questionário aos encarregados de educação dos estudantes que frequentam uma das escolas na área. Os questionários incluíram perguntas relacionadas com os seguintes temas: i) o comportamento no atravessamento enquanto peão, ii) o comportamento no atravessamento enquanto condutor, iii) a percepção em relação aos riscos no atravessamento. Estes questionários foram impressos e distribuídos pelos estudantes, que posteriormente os entregaram aos seus encarregados de educação para o seu preenchimento. Dos 150 questionários entregues na escola existente na área, foram recepcionados 138. Juntaram-se a estes questionários outros 12 realizados à porta da escola e que foram respondidos por pessoas que usam a passadeira.

\section{Contributos do estudo empírico}

O estudo realizado reitera as ideias anteriormente apresentadas acerca da relevância de conhecer mais profundamente as tomadas de decisão sobre a localização e o tipo de travessias pedonais, bem como os seus usos sociais nas cidades.

Tal como foi descrito, a travessia pedonal de nível sem sinais luminosos observada localiza-se em frente a uma escola que recebe estudantes de muitas áreas do concelho e dos concelhos vizinhos e serve a passagem de peões que usam os serviços (correios, agências imobiliárias, agências bancárias e pequeno comércio) e/ou habitam na área circundante, onde se registam cerca de 1000 habitantes (dados de 2019). As travessias vizinhas distam alguns minutos a pé (cerca de 2 a 3 minutos a jusante e a montante) e, pela sua localização menos central nos referidos trajectos, são menos utilizadas.

\section{Contributos da observação directa}

Da análise da informação recolhida através de vídeo, foram observados 2842 indivíduos na 
travessia. Destes, $81 \%$ são adultos, $14 \%$ crianças e $5 \%$ são idosos. Na maioria, são mulheres (58\%). Da observação conclui-se que $92 \%$ dos indivíduos olham para os dois lados (direita e esquerda), antes de iniciar a travessia, e $8 \%$ olham apenas para um. A grande maioria dos sujeitos observados (86\%) não pára antes de iniciar o atravessamento da passadeira. Só $14 \%$ o faz. Muitos dos utilizadores desta travessia pedonal são crianças. Quando acompanhadas por adultos, estas crianças atravessam pela mão, tal como alguns idosos (Figura 1), e sem revelar comportamentos de risco. Todavia, quando atravessam sozinhas, apresentam vários comportamentos menos cautelosos: passam a correr (Figura 4), a brincar, a usar aparelhos electrónicos e a conversar (Figura 3).

Além disso, tendem a não olhar para ambos os lados da estrada, ou a não aguardar que os automobilistas parem. Os idosos atravessam normalmente em marcha rápida, mas, por norma, aguardam a paragem dos automóveis, aproveitando para fazer acenos de agradecimento aos automobilistas. A observação permite estabelecer algumas conclusões acerca dos automobilistas e sobre as formas como abordam as travessias. Tal como as imagens demonstram, há condutores que não param, mesmo avistando o peão. Num total de 2726 atravessamentos observados, os carros, em 2639 dos casos, em vez de pararem, só abrandaram. Observa-se, aliás, e com regularidade, que há carros a pararem sobre a travessia (Figura 2).

Figura $1 \triangleright$ Automobilistas que não param perante a presença dos peões na travessia pedonal

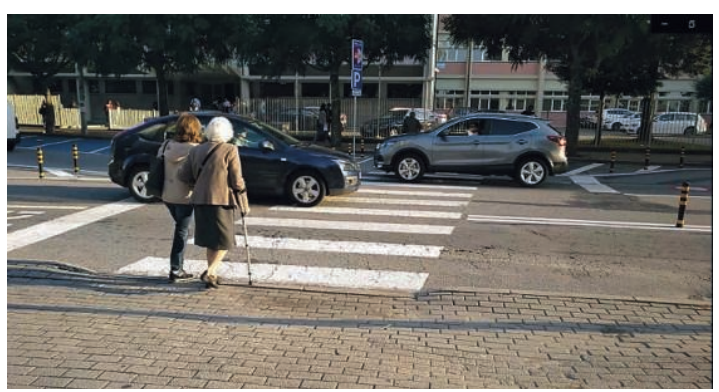

Autora: Márcia Silva.

Figura $2 \triangleright$ Automobilista que pára sobre a travessia pedonal

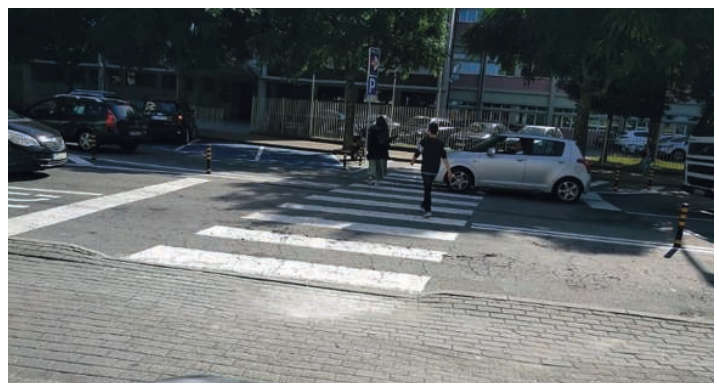

Autora: Márcia Silva.
Figura $3 \triangleright$ A distracção no atravessamento

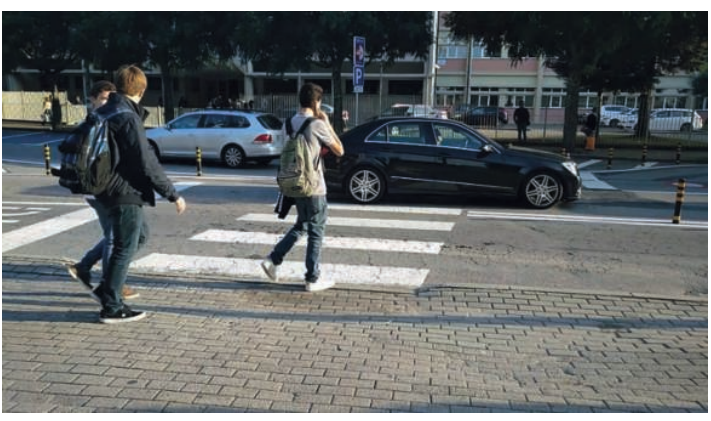

Autora: Márcia Silva.

Figura $4 \nabla$ Criança a correr durante o atravessamento

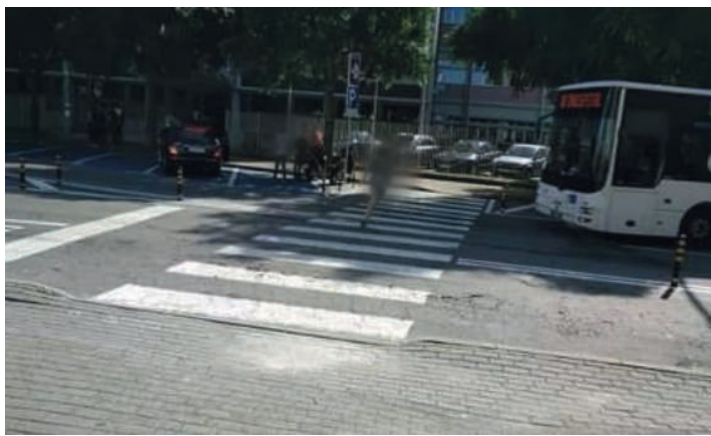

Autora: Márcia Silva.

Contributos do inquérito por questionário aos encarregados de educação

Em suma, a passadeira oferece-se a alguns comportamentos de risco que foram visíveis e são demonstráveis através do registo vídeo e do registo visual, através de fotografia.

A informação recolhida através da observação directa é completada com os dados provenientes do inquérito por questionário proposto aos pais das crianças que frequentam a escola situada em frente da travessia estudada, os quais fornecem alguma informação adicional relevante.

Foram analisadas 150 respostas e a maior parte dos participantes no questionário são pessoas com o ensino superior (79\%) e com filhos cujas idades se situam entre os 4 e os 12 anos de idade. A maioria (82\%) afirma usar frequentemente a travessia pedonal para aceder à escola e/ou a serviços existentes na área. Do total dos respondentes ao questionário, $27 \%$ afirma que há problemas de segurança nesta travessia.

A ausência de sinais luminosos é apontada como o principal motivo de preocupação. A maioria dos inquiridos assinala que tem comportamentos adequados ao atravessamento pedonal e que aconselha frequentemente as crianças a "parar e olhar para os dois lados" $(n=54)$, "parar e atravessar quando 
os carros pararem" $(n=20)$, ter "muita atenção e prudência" ( $n=4)$ e "nunca atravessarem sozinhos" $(n=7)$. Um dos conselhos citados pelos pais consiste em "nunca largar a mão". Ainda relativamente ao comportamento na travessia, $61 \%$ dos inquiridos afirmam verificar se as crianças sabem atravessar, sendo que $57 \%$ afirmam não permitir que os seus filhos atravessem sozinhos (particularmente quando menores, com idade abaixo dos 13 anos).

\section{Para uma política no âmbito das travessias pedonais}

O estudo empírico conduzido demonstra que as travessias pedonais são um meio organizador do espaço nas cidades. Na cidade de Braga, como na maior parte das cidades portuguesas, coexistem diversos tipos de travessias. As mais frequentes são ainda as travessias de nível com sinais luminosos e as travessias de nível sem sinais luminosos. As primeiras potenciam, à partida, maior segurança, por delimitarem compassos de espera para a passagem de automóveis e peões. O segundo tipo de travessia apontado é mais económico e aparentemente mais ágil do que o anterior, por supor que tanto os peões como os condutores de veículos automobilizados respeitam as cedências esperadas. Todavia, tal como demonstrámos através dos resultados deste estudo, este modelo de travessia comporta níveis elevados de insegurança e oferece, por isso, muitos riscos.

A população mais idosa e com dificuldade motora e/ou visual, assim como as crianças e adolescentes, estão mais expostas a esses riscos. Actualmente, a evolução científica e tecnológica tem permitido criar variações nos modelos de travessia. Tem sido implementado um número crescente de travessias "inteligentes" nas cidades, porém, na sua maioria, esta travessia não representa acréscimo de segurança e prevenção de acidente. Assentes no princípio da redução do tempo de espera de paragem do automóvel, este perfil de travessia mantém muitas das implicações das travessias de nível sem sinal luminoso.

Em suma, o estudo realizado, ainda que centrado sobre a observação dos usos de uma travessia, permite reforçar a necessidade de conceber a travessia pedonal não como uma mera obra de engenharia, cuja função imediata é organizar a rota para a circulação de pessoas no espaço físico, mas como um elemento central na organização de várias dimensões da vida diária dos cidadãos, que afecta as sociabilidades e que tem influência na amplitude e formas de apropriação e vivência do espaço da cidade. Quer isto dizer que as travessias pedonais são algo para o qual se precisa apontar a política de organização da própria cidade, particularmente em contextos de crescimento das mobilidades e de reforço de medidas de descarbonização e combate a alterações climáticas. O tempo das famílias e as desigualdades de género na família são também assuntos a pensar em articulação com as temáticas das travessias pedonais e da segurança rodoviária, uma vez que as próprias travessias podem ser pensadas como estruturas de tempo e de ritmos.

\section{Considerações finais}

Na sequência do ponto anterior, a informação recolhida permite concluir que o atravessamento das travessias pedonais é um problema que exige intervenção a três níveis: i) no debate e esclarecimento sobre as implicações decorrentes do desenho e da implementação de travessias para a segurança das populações e políticas públicas de prevenção rodoviária, organização e planeamento do espaço; ii) na promoção da participação e do conhecimento dos públicos sobre travessias pedonais e modos de uso, não linearmente dirigida pelo princípio da obediência a normativos; e iii) em termos regulatórios, através do estudo e implementação de medidas de promoção da circulação a pé que respondam a desígnios de mudança do modo de vida nas cidades.

$O$ resultado do percurso feito através da participação no projecto BUILD, para o caso concreto da travessia situada na freguesia de São Vicente, em Braga, sublinha a importância da prudência, principalmente por parte dos tomadores de decisão, a respeito da adopção imediata de soluções tecnológicas com sistemas automáticos. Isto porque, pelo local onde estão e pelos fluxos que comportam, tais soluções podem pôr em causa a segurança ou ser ineficazes em termos de regulação de fluxos de passantes. É o que ocorre no caso desta travessia analisada que se situa em frente a uma escola e que concentra (a norte) uma vasta oferta de serviços de proximidade.

Concluímos ser densamente complexa a teia de variáveis que rodeiam a construção social da travessia pedonal. Torna-se crucial auscultar a população e investir, tanto em mudanças estruturais no espaço que combinem os objectivos de aumento da qualidade de vida nas cidades e que exigem posicionamentos políticos concertados, como em medidas socioeducativas de promoção da cidadania e de combate à iliteracia de circulação, uma vez que as travessias pedonais, como qualquer outro, é um território onde se reflectem valores e estilos de vida, o que é igualmente válido para peões e condutores.

Tal como se foi anotando ao longo do texto, a problematização sociológica das travessias pedonais realizada é ainda preliminar e implica aprofundamento, nomeadamente através da expansão do estudo noutros locais e noutras cidades. No caso estudado, os resultados permitem demonstrar o interesse em combinar os contributos das disciplinas 
tecnológicas e das ciências sociais, nomeadamente acerca do entendimento do espaço.

Interessaria ainda aprofundar, por parte da Sociologia, o conhecimento acerca dos pressupostos políticos, ideológicos e científicos que continuam a presidir à definição do local e do tipo de passadeira a implementar. Isto na medida em que os resultados deste pequeno estudo nos indicam persistirem muitas contradições entre aqueles que são os desígnios da sustentabilidade, principalmente do ponto de vista ambiental e da qualidade de vida nas cidades, e a forma como novos meios de transporte, reconfigurações e mudanças nos espaços físicos alteram e obrigam a adaptações indesejadas por parte das populações. É neste sentido que, sublinhando a relevância de promover diagnósticos qualitativos sobre os modos de uso das travessias pedonais, se reitera a necessidade de estas serem compreendidas não como meras obras de engenharia, mas como objectos de política, que interferem nos modos de vida e que afectam a vida dos cidadãos.

\section{Agradecimentos}

As autoras agradecem o apoio no âmbito do projecto BUILD - Braga Urban Innovation Laboratory Demonstrator, financiado pelo Fundo Ambiental e pela Câmara Municipal de Braga, e ao projecto UIDB/00736/2020 - Centro de Estudos de Comunicação e Sociedade. Agradecem também as preciosas apreciações realizadas pelos revisores anónimos da revista Forum Sociológico.

\section{Referências bibliográficas}

Ariotti, P., Cybis, H., \& Ribeiro, J. (2006). Fatores intervenientes no comportamento de pedestres em travessias semaforizadas: Uma abordagem qualitativa. Transporte em Transformação. In $X X$ CNT/ANPET, Brasília.

Autoridade Nacional de Segurança Rodoviária (ANSR). (2018). Relatório de sinistralidade no Distrito de Braga. Disponível em http://www.ansr.pt/ Estatisticas/RelatoriosDeSinistralidade/Pages/ default.aspx

Beck, U. (2011). Risk society: Towards a new modernity. Londres: Sage Publications.

Cambon de Lavalett, B., Tijus, C., Poitrenaud, S., Leproux, C., Bergeron, J., \& Thouez, J. P. (2009). Pedestrian crossing decision-making: A situational and behavioral approach. Safety Science, 47, 12481253. doi: 10.1016/j.ssci.2009.03.016

Campos, R. (2011). Imagem e tecnologias visuais em pesquisa social: Tendências e desafios. Análise Social, XLVI(199), 237-259.

Cresswell, T. (2010). Towards a politics of mobility. Environment and planning. Society and Space, 28(1), 17-31.
Goh, B., Subramaniam, K., Wai, Y., \& Mohamed, A. (2012). Pedestrian crossing speed: The case of Malaysia. International Journal for traffic and transport engineering, 2(4), 323-333. doi: 10.7708/ ijtte.2012.2(4).03

Gualberto, F., \& Barbosa, H. (2016). Estudo dos fatores que influenciam o comportamento de pedestres em travessias de vias urbanas. In $X X X$ Congresso Nacional de Pesquisa em Transporte da ANPET (Vol. I) (pp. 1909-1920). ANPET. Disponível em https:// www.researchgate.net/publication/315194399

Harvey, D. (1989). The condition of postmodernity: An enquiry into the origins of cultural change. Oxford: Blackwell.

Harvey, D. (2012). Rebel cities. Londres: Verso.

Ibrahim, N., Kidwai, F., \& Karim, M. (2005). Motorists and pedestrian interaction at unsignalised pedestrian crossing. Journal of the Eastern Asia Society for Transportation Studies, 5, 120-125.

Latour, B. (2005). Reassembling the social. An introduction to Actor-Network-Theory. Oxford: Oxford University Press.

Liu, R., Silva, J., \& Seco, A. (2000). A bi-modal microsimulation tool for the assessment of pedestrian delays and traffic management - Comunicação apresentada no 9th International Association of Travel Behaviour Research Conference, Gold Coast.

Massey, D. (1994). Space, place and gender. Cambridge: Polity Press.

Pais, J. M. (2010). Lufa-lufa quotidiana. Lisboa: Imprensa de Ciências Sociais.

Premebida, A., Neves, F., \& Darte, T. (Orgs.) (2015). Investigações contemporâneas em estudos sociais da ciência e tecnologia. Jundiaí: Paco Editorial.

Sales, C. (2018). Mobilidades em português: Paradigma, cultura e potencialidades. In E. Araújo, R. Ribeiro, \& R. Costa (Eds.), Viver emla mobilidade (pp. 10-22). Braga: CECS.

Seco, A., Macedo, J., \& Costa, A. (2008). Manual de planeamento da acessibilidades e da gestão viária: Os peões (Vol. VIII). Porto: Comissão de Coordenação e Desenvolvimento Regional do Norte (CCDR-N), Ministério do Ambiente e do Ordenamento do Território.

Sheller, M. (2004). Automotive emotions: Feeling the car. Theory, Culture \& Society, 21(4-5), 221-242. doi: $10.1177 / 0263276404046068$

Sheller, M. (2011). Mobility. Sociopedia.isa, 1-12. doi: $10.1177 / 205684601163$

Silva, M., Araújo, E., \& Ribeiro, R. (2019). Relatório sobre usos e desusos da passadeira. Braga: Centro de Estudos Comunicação e Sociedade e Câmara Municipal de Braga.

Sisiopiku, V., \& Akin, D. (2003). Pedestrian behaviours at and perceptions towards various pedestrian facilities: An examination based on observation and survey data. Transportation Research Part F, 6, 249-274. doi: 10.1016/j.trf.2003.06.001 
Soja, E. (1989). Postmodern geographies: The reassertion of space in critical social theory. Londres: Verso Press.

Tiwari, G., Bangdiwala, S., Saraswat, A., \& Gaurav, S. (2007). Survival analysis: Pedestrian risk exposure at signalized intersections. Transportation Research Part F, 10, 77-89. doi: 10.1016/j.trf.2006.06.002
Urry, J. (2004). The system of automobility. Theory Culture \& Society, 21(4-5), 25-39.

Urry, J. (2005). Sociologie des mobilités: Une nouvelle frontière pour la sociologie?. Paris: Éditions Armand Colin.

Webster, A. (1991). Science, technology and society. Rutgers University Press: New Brunswick.

Márcia Silva. Centro de Estudos de Comunicação e Sociedade, Instituto de Ciências Sociais, Universidade do Minho \& Instituto de Ciências Sociais, Universidade do Minho. Campus de Gualtar, 4710-057 Braga, Portugal. Email: marciasilva.formacao@gmail.com

Emília Araújo. Centro de Estudos de Comunicação e Sociedade, Instituto de Ciências Sociais, Universidade do Minho \& Departamento de Sociologia, Instituto de Ciências Sociais, Universidade do Minho. Campus de Gualtar, 4710-057 Braga, Portugal. Email: era@ics.uminho.pt

Rita Ribeiro. Centro de Estudos de Comunicação e Sociedade, Instituto de Ciências Sociais, Universidade do Minho \& Departamento de Sociologia, Instituto de Ciências Sociais, Universidade do Minho. Campus de Gualtar, 4710-057 Braga, Portugal. Email: rmgr@ics.uminho.pt 